\title{
La estrategia en las redes de una marca de moda
}

\section{The network strategy of a fashion brand}

\author{
Bienvenida Araceli Parres Serrano. Universidad Alcalá de Henares. España. \\ araceli.parres@edu.uah.es \\ $[\mathrm{CV}](\mathrm{G}$ \\ Francisco García García. Emérito de la Universidad Complutense de Madrid. España. \\ fgarciag@ucm.es \\ $[\mathrm{CV}]$ (1)
}

Eva Matarín Rodríguez-Peral. Universidad Rey Juan Carlos. España.

eva.matarin@urjc.es

$[\mathrm{CV}]$ (1)

\author{
Cómo citar este artículo / Referencia normalizada \\ Parres Serrano, B. A., García García, F. y Rodríguez-Peral, E. M. (2020). La estrategia en las \\ redes de una marca de moda. Revista Latina de Comunicación Social, (77), 33-53. \\ https://www.doi.org/10.4185/RLCS-2020-1448
}

\section{RESUMEN}

Este artículo analiza las nuevas formas de comunicación y sensibilización, en concreto en el ámbito digital a través de un estudio de caso de la marca de moda ECOALF, única en el mundo por su aportación al sector a través de la limpieza de los océanos. El uso de la expresión ilimitada que realiza ECOALF a través de medios digitales desemboca en la concienciación medioambiental, mensaje clave de sus estrategias tanto online como offline. Se trata de una práctica corporativamente responsable en el medio digital, en especial de sus redes sociales, con las que se comunica interactivamente y desea inspirar al prosumidor a través del contenido de sus publicaciones. Se profundizará en cómo transmite su propósito empresarial específicamente online y sus buenas prácticas corporativas a través de Instagram, Facebook, Twitter, así como de su página Web. Se procede a través de la aplicación de una metodología cualitativa, utilizando procesos de categorización, apoyada en el análisis del discurso y el software NVIVO11 donde se han analizado las publicaciones online de la compañía de los últimos cinco años. Como conclusión se descubre los valores principales que transmite la marca a través de su lenguaje visual, de su lenguaje escrito y la complementariedad entre ambos a la hora de construir sus estrategias online. Además, se podrá apreciar cómo la empresa de moda convierte su proceso de producción en material audiovisual para utilizarlo con fines de concienciación medioambiental a nivel mundial para diferentes consumidores de moda, de redes sociales, ecologistas, líderes culturales y cazadores de tendencias entre otros sin olvidar la labor de alfabetización digital que se desprende de todo ello.

PALABRAS CLAVE: comunicación digital; ECOALF; moda; Slow; redes sociales; sostenibilidad; estrategia.

\section{ABSTRACT}

This article analyzes the new forms of communication and awareness, specifically in the digital field through a case study of the ECOALF fashion brand, unique in the world for its contribution to the 
sector through the cleaning of the oceans. The use of unlimited expression by ECOALF through digital media leads to environmental awareness, a key message of its online strategies. It is a corporately responsible practice in the digital medium, especially of its social networks with which it communicates interactively and inspires the prosumer. It will deepen in how it transmits its business purpose and its good corporate practices through Instagram, Facebook, Twitter, as well as its website. A qualitative methodology is applied, using categorization processes, supported by discourse analysis and NVIVO11 software where the company's online publications from its first five years have been analyzed. As a conclusion, the main values that the brand transmits are discovered through its written language and the visual besides its complementarity between both languages when it comes to building their online strategies. In addition, you can see how the fashion company converts its production process into audiovisual material to be used for environmental awareness purposes worldwide for different fashion consumers, social networks, ecologists, cultural leaders and trend hunters, among others, without forgetting the digital literacy work that emerges from all this.

KEYWORDS: digital communication; ECOALF; Slow; fashion; social networks; sustainability; strategy.

\section{CONTENIDOS}

1. Introducción. 1.1. El entorno digital y la moda. 1.2. La sostenibilidad y la moda. 1.3. La alfabetización digital y la experiencia de usuario -UX- en la moda. 2. Método. 2.1. Objetivos generales. 2.2. Enfoque metodológico. 2.3. Material. 3. Resultados y discusión. 3.1. Atributos analizados. 3.2. Estrategias. 3.2.1. Estrategia Comercial. 3.2.2. Estrategia de sensibilización. 3.2.3. Estrategia informativa. 3.3. Alfabetización a través de la UX. 3.4. Frecuencia y representación de relaciones. 4. Conclusiones. 5. Referencias.

\section{Introducción}

Este artículo profundiza en cómo una firma de moda caracterizada por la innovación en torno a la sostenibilidad como principal atributo de marca, va más allá de los métodos tradicionales de comunicación para extender, fortalecer y promover la experiencia del usuario/a con la marca a través de los canales digitales. Se parte del concepto de marca aportado por Kapferer al definirla como un conjunto de signos ligado a los productos acreditando el origen y que establecen una diferencia con su competencia (Kapferer, 2006, p. 37).

El origen en este caso es la misión de Goyeneche -fundador de la marca- de crear moda sostenible a través de una marca con filosofía Slow -se definirá más adelante- que nace "para mejorar el mundo" según palabras de su presidente y fundador. La propia Web de ECOALF señala que:

ante la frustración por el uso excesivo de los recursos naturales del mundo y la cantidad de

residuos producidos por los países industrializados. El objetivo es fabricar la primera generación de productos de moda realizados con materiales reciclados de la misma calidad, diseño y propiedades técnicas que los mejores productos no reciclados. (Goyeneche, 2009)

La actividad digital de la marca gira en torno a la misión de crear la primera generación de productos reciclados con la misma calidad y diseño que los mejores no reciclados. Por tanto, en base a los principios de la economía circular referidos a que los desechos plásticos recogidos en los océanos pueden volver a entrar en el ciclo de producción (Magnier, Mugge y Schoormans, 2019, p. 84) su 
sostenibilidad se basa en el reciclaje para crear sus tejidos con un objetivo a largo plazo: representar los tejidos de las nuevas generaciones, con lo que el desarrollo del modelo de negocio se realiza invirtiendo en I+D por medio de su propia Fundación.

A través de la integración de tecnología punta crean prendas de vestir y accesorios hechos a partir de materiales reciclados sin que lo parezcan. Actualmente la compañía tiene once alianzas activas en diferentes puntos geográficos (Taiwán, Corea, Portugal, Méjico, Japón, España..., etc.) que permiten estar continuamente desarrollando todos los elementos necesarios para poder fabricar con origen reciclado.

Ante el contexto de que las tecnologías, en referencia al consumo, son "fuerzas poderosas que actúan para cambiar la forma de esa actividad y su significado" (Winner, 2004, p. 105), ello unido a "el culto a la velocidad" (Honoré, 2012, p. 13) que conlleva la actividad social deriva en que "todo hay que hacerlo deprisa: pensar deprisa, innovar deprisa, comunicar deprisa" (Camps, 2003, p. 31). Así que la marca trabaja para posicionarse como un referente en la comunidad digital para que la experiencia del/a usuario/a sea global abarcando, enlazando y complementando la comunicación online con la offline. Esto es, la práctica digital se transmite a través de sus Redes Sociales (RRSS); la parte intelectual por la labor de la empresa en torno a su mensaje medioambiental que la convierte en única frente a la sociedad y en el tejido empresarial; físicamente se traduce en el punto de venta y el mismo producto. La palabra "referente" utilizada por la misma directora de comunicación de ECOALF, Álvarez de Ossorio, tiene especial relevancia en la investigación ya que apunta directamente al objetivo conceptual de la misión corporativa.

Este universo formado por la parte digital junto con la física y conceptual se estudia para investigar las estrategias comunicativas que la marca emplea para sensibilizar a los receptores. Esta labor se ejecuta a través de sus mensajes en torno a los valores medioambientales que la marca difunde a la comunidad digital a través de sus estrategias y contenidos publicados en RRSS y su Web. Se trata de analizar varios elementos clave para discernir este conjunto de ECOALF en RRSS donde educa y comunica a la sociedad. Los componentes que se van a afrontar serían: la Experiencia del usuario o user experience (UX) término en inglés y extendido indistintamente en los diferentes entornos geográficos. Ésta refuerza cualquier comunicación digital para trasladar sus efectos a un escenario físico. La ISO 9241-210, International standard on ergonomics of human system interaction, la define como un conjunto de factores y elementos relativos a la interacción del usuario con un entorno o dispositivo concretos, dando como resultado una percepción positiva o negativa de dicho servicio, producto o dispositivo. La cultura participativa y la sensibilización (Jenkins, 2006) de los jóvenes, quienes tienen como referentes las nuevas tecnologías, se basa en la necesidad de desarrollar su conciencia digital. Para ello es necesario que perciban los usos y riesgos asociados a estas nuevas formas de expresión, apoyando así los nuevos canales de sensibilización. Ello está estrechamente relacionado con la alfabetización multimedia entendida a su vez como la habilidad a desarrollar por la población y que "para el siglo XXI, ha de ser mediática, digital, multimodal, critica y funcional" (Gutiérrez y Tyner 2012, p. 37).

Según Girón, el 75\% de los consumidores que realizan una compra lo hacen tras una consulta online, lo que indica la importancia de este medio para la industria. Se trata de una inversión en comunicación del $15 \%$ al $20 \%$ de las cifras de negocio (Campuzano, 2016, p. 11). Otro punto orientativo en esta investigación es la sostenibilidad definida en el Glosario sobre Responsabilidad Social para la Investigación y el Debate Terminológico (Benavides, 2012) dependiendo de si el concepto sea aplicado al desarrollo o a la economía, es decir, no se sostiene por sí mismo, sino que depende del proceso económico. Si se retrocede en el tiempo, ya en 1988 la Comisión Mundial sobre Medio Ambiente y Desarrollo (CMMAD) especificaba que el desarrollo sostenible es el que satisface 
las necesidades de la generación presente sin comprometer la capacidad de las generaciones futuras para cubrir sus propias necesidades.

\subsection{El entorno digital y la moda}

La globalización y la realidad de que internet es hegemónico (Berners y Fischetti, 2000) ha dado lugar a que los consumidores se reúnan en comunidades online de manera virtual convirtiéndose, en consecuencia, las plataformas sociales en canales fundamentales para las estrategias empresariales (Lacasa, 2017). Los medios digitales se conciben como nuevas formas que permiten mediar y representar el mundo, lo que se transforma en un nuevo espacio de comunicación (Quiroz, 2010) y es así cómo lo establece ECOALF.

La irrupción de Internet en los métodos de expresión y comunicación habituales en la sociedad (Girón, 2018) hacen necesaria la comprensión de los mismos para los/as usuarios/as. Estos medios de expresión facilitan la interacción entre individuos y la marca facilitando así la creación de grupos de interés digitales ya sea en un objeto particular, o un área, o estilo de vida general ya que la presencia en RRSS busca una interacción con la comunidad (Mir, 2016). Todo ello, en el caso corporativo, se trasladaría al deseo de posicionarse en la comunidad formada por los públicos objetivos de la marca y escucharles, intercambiar ideas o sencillamente informarles o posicionarse como referente (Lacasa, 2017).

En España, el 93\% del total de la población tiene acceso a la Red según el informe Global Digital 2019. A nivel nacional existen cerca de 37,5 millones de usuarios de RRSS, dato que concierne al $78 \%$ de la población total del país. Esta cifra demuestra la relevancia de las RRSS como canales de comunicación, transmisión de mensajes y por tanto de su influencia en la creación de realidades, conceptos y comportamientos en el entorno natural de los usuarios (Lacasa, 2017). Es importante recordar que las RRSS llegaron a la vida ordinaria en 1997 a través del Messenger y el mapa actual de redes se configura, a partir del criterio de la investigadora, a partir del 2004 con Facebook, en definitiva, la red social con más usuarios del mundo. Un site en el que, como describe Moreno en su libro sobre redes, el usuario únicamente se dedica a aceptar con rapidez las condiciones de uso (Moreno, 2015). Cada uno de esos usuarios tiene una motivación diferente para registrarse en esa red y 9 de cada 10 usuarios habituales de la Red tienen siempre uno abierto.

En el caso de Instagram, Lacasa afirma que su popularidad se debe a la instantaneidad con la que se genera información visual apoyada en breves textos, lo que crea una sensación de cercanía a otros usuarios. Aunque puede resultar sencillo hacer fotografías y producir montajes audiovisuales no todos tienen la misma calidad de expresión adecuada al mensaje corporativo deseado, estilo y objetivo de reacción en el destinatario como concluye la autora.

El objetivo más perseguido de cualquier empresa es conseguir que se hable del producto, de la firma. Ahora mismo el medio online responde a estas intenciones o necesidades comerciales de popularidad. El portal lovemarks.com anima a los fans que cuenten sus historias de amor con sus marcas queridas, aquellas con las que establecen lazos emocionales. Ésta sólo es una iniciativa digital, de entre muchas otras, donde se crean vínculos afectivos con las empresas y se traspasa la barrera física junto con la firma de moda para conectar y compartir la experiencia en un entorno virtual.

El fundador de la agencia de publicidad de marcas premium Greenhill + Partners de Nueva York, Greenhill, habla de las posibilidades que ofrece el medio online ya que permite a la firma dirigirse 
tanto al cliente como al consumidor aspiracional. Esto no sucede de igual modo con la prensa escrita o los medios tradicionales por la carencia de interactuación inmediata.

El mismo autor apunta a la conversación online donde la protagonista es la marca y apuesta por invitar a los usuarios a que hablen de ella y así crear un sentimiento de exclusividad que no lograrían de otra forma. Todo ello sin descuidar la experiencia de usuario digital en la que ECOALF ha trabajado y lo deja patente puesto que en dos años ha materializado tres cambios importantes de mapa web con el fin de amoldarse a las nuevas tendencias digitales.

\subsection{La sostenibilidad y la moda}

Si los atributos de una marca son el equivalente a un ingrediente o algo que le provee significado (Otaduy, 2012, p. 70), uno de los principales de ECOALF es la innovación junto con la sostenibilidad y la historia. Estos los transmite a sus públicos a través de dos lenguajes complementarios, en ocasiones: visual y escrito.

La empresa mantiene una discurso en torno a la sensibilización en la sociedad, "no es necesario seguir abusando de los recursos naturales de una forma indiscriminada" tal y como se relata en la web ecoalf.com. A través de su Fundación y con esta filosofía descubren en la limpieza del plástico en los océanos, "una fuente de materia prima para innovar en la realización de tejidos que, junto con su diseño convierten su actividad empresarial en una vía de mejorar el mundo" (ECOALF, 2009).

Ante este contexto, donde la instantaneidad ya no solo en el impacto de los mensajes sino en el consumo, se ha impulsado la creación de una regulación orientativa para el tejido empresarial internacional por parte de Naciones Unidas (ONU) a través de la implantación de los Objetivos de Desarrollo Sostenible (ODS). Se trata de diecisiete directrices para que las empresas, al margen de su localización geográfica y su actuación, mejoren el entorno físico y la comunidad social existente para que su actividad empresarial suponga un bien común. Estos 17 ODS contemplan: la eliminación de la pobreza y del hambre, el cuidado de la salud, alfabetización, igualdad de género, acceso al agua y a la higiene, la implantación de energía no contaminante, trabajo digno, innovación en la industria, erradicar la desigualdad, conseguir ciudades sostenibles, consumo responsable, cuidar el clima, flora, fauna y conseguir instituciones sólidas y relaciones para conseguir objetivos, además de la paz.

Este concepto no solo abarca la producción de artículos, sino que apunta al mismo origen de la materia prima estableciendo y/o exigiendo así una transparencia en la totalidad del proceso de creación de cualquier producto. Esta información en cada una de las fases por las que pasa un objeto hasta su punto de venta obtendría el nombre de trazabilidad. Este nuevo concepto, que entra en escena y, que podría implicar otros elementos como la sostenibilidad. Esta última es definida por la CMMAD en el 1988 como el desarrollo que satisface las necesidades de la generación presente sin comprometer la capacidad de las generaciones futuras para satisfacer sus propias necesidades.

En este punto Slow Fashion cobra protagonismo. Este término, creado por Fletcher (2014), es una tendencia que tiene por objeto hacer frente al fenómeno Fast Fashion. Se trata de crear muchas más colecciones de ropa que las clásicas Primavera-Verano y Otoño-Invierno en periodos de tiempo cada vez más breves. La Slow Fashion "is to clothing and design what slow food is to cuisine -natural, ethical, local (...) Slow Fashion means you can look fantastic and feel 100\% guilt free" (Wander, 2009, p. 33). En este punto, Girón (2010) identifica para el sector, una oportunidad de transformar lo sostenible en aspiracional. Lo que puede significar un reenfoque empresarial orientado a la responsabilidad para con el entorno donde produce y hacia quienes lo hace en línea con la tesis de Girón (2010) quien señala que los consumidores son conscientes de que, tras la belleza de los 
objetos, en ocasiones lo que se encuentra es una historia de vertidos que suponen un riesgo para la salud de los trabajadores (Girón, 2010).

Cabe realizar un apunte en lo referente a la relación entre el reciclaje, concepto principal de inspiración de ECOALF, y la sostenibilidad. El reciclaje es un proceso a partir del cual un producto usado, generalmente de desecho, es sometido a un tratamiento especial que le devuelve su utilidad y por tanto se convierte en un nuevo producto para consumir o bien permite emplear su materia prima para la generación de otros productos u objetos. Si bien no todos los desechos que producen los seres humanos en el día a día son plausibles de reciclamiento lo importante es saber dilucidar cuáles sí lo son como confirma la directora de comunicación de ECOALF. Reciclar determinados productos puede resultar más perjudicial que emitirlos de nueva creación, algo que ha valorado la empresa estudiada.

La difusión y la concientización del reciclaje no son iguales en todo el mundo. Es una labor en la que la alfabetización digital y las publicaciones online de esta marca tienen como premisa en su estrategia online y con el apoyo offline de la propia prenda pues "no es igual que promocionar cualquier otro bien de gran consumo (...) al ser la moda una forma de comunicación y producir mensajes, se comunica por sí misma” (Saviolo y Testa, 2007, p. 274).

Los resultados de la investigación contribuirán a comprender la inspiración del modelo de negocio de la marca como expresión del activismo de la moda. En la actualidad existe un tipo de cliente -que va en aumento- que cuida el planeta y su salud. Estos desarrollan una predilección por lo artesanal (Vartan, 2008), y afirma en pro del ritmo de consumo "ayudar a los demás a través de las compras se puede considerar una especie de lujo", lo que puede corroborar las posibilidades de hacer de ECOALF una marca activista a través de su: Because there is no planet $B$, porque no hay un planeta $\mathrm{B}$, y que se logre por tanto el lujo de ayudar al mundo a través de su consumo. La suma de los factores conduciría a una sensibilización con un consecuente cambio en el hábito de consumo de la moda en la sociedad a través del alcance digital.

\subsection{La alfabetización digital y la experiencia de usuario -UX- en la moda}

Según Gilster (1997), la alfabetización digital es la capacidad de comprender y utilizar la información de fuentes diversas y múltiples formatos teniendo en cuenta que el autor enmarca la definición en un universo que gira en torno a la Red. De esta línea de pensamiento se desprende el término experiencia de usuario (UX) creado por Norman en los laboratorios de Apple. Ésta se basa en la Interacción Persona-Ordenador (HCI, Human-Computer Interaction, Card, 1983) centrado en el fenómeno de interacción entre usuarios y sistemas informáticos para desarrollar métodos y prácticas para el diseño de productos interactivos. Ante este contexto la marca llevaría a cabo su labor de alfabetización a partir de las enseñanzas de UX para crear los elementos que identificamos en las RRSS de la firma. Estos responden a:

- Arquitectura de la información (AI): facilita la conexión entre el/la usuario/a y la información de forma que crea una jerarquía en el contenido. Prima la facilidad en el hallazgo de la información en el canal digital.

- Diseño de interacción: aborda lo relativo a la parte más visual del contenido como es el caso de las imágenes, color, iconos, entre otros.

- Usabilidad: se trata de la validez del diseño, de la organización de contenidos en equilibrio con los intereses comerciales de la compañía.

- Diseño visual: la estética visual es fundamental para transmitir también los valores de la marca. 
ECOALF ha sufrido diferentes cambios en su visual online con el fin, ya no de adaptarse mejor al medio digital sino de alcanzar una mejor comunicación de su identidad. De ahí que sus fotografías y su Web reflejen un diseño mínimo que se centra más en fotos de productos y ventas, sin anuncios adicionales, con una interfaz bien diseñada, con un menú visible a través del cual se puede acceder a todas las familias de productos accesibles vía web. En referencia a los tonos siempre intentar recordar a un entorno neutro que pueda encajar a nivel intercultural e internacional. El mensaje siempre está presente en cualquiera de las páginas que se visiten de la Web, incluso en Instagram. La estrategia actual intercala imágenes de diseños variados con imágenes de diseños que portan el lema "activista" de la firma de moda: porque no hay un planeta B. Todo ello con una fuente de letra básica y neutra como el resto de componentes.

\section{Método}

\subsection{Objetivos generales}

Los objetivos generales planteados corresponden a los siguientes:

- Analizar las estrategias comunicativas que la marca emplea para formar a los receptores activos a través de sus mensajes.

- Identificar los valores medioambientales que la marca difunde a la comunidad digital a través de sus estrategias y contenidos publicados en RRSS.

- Valorar cómo la comunicación digital y la sensibilización aparecen relacionadas.

\subsection{Enfoque metodológico}

El análisis se lleva a cabo a través de una metodología mixta que combina la técnica cualitativa de la que parte el análisis de contenido y del discurso, además de las relaciones cuantitativas que surgen de las tendencias de frecuencias respecto a los resultados. Para ello se ha empleado el programa informático NVIVO11. Éste es un software que se utiliza para el tratamiento de datos, su organización y exploración de la información con el fin de facilitar y optimizar el trabajo de análisis en investigaciones cualitativas o mixtas. Esta herramienta permite explorar diferentes variaciones discursivas de la marca con la codificación de los datos aportados por el análisis del corpus de las publicaciones de ECOALF desde diciembre de 2013 a diciembre de 2018 dado que es el periodo que abarca la consolidación de la estrategia en RRSS. A partir de ese año se experimenta un cambio en el responsable de estrategia de RRSS, que supone un aumento de actividad digital de publicaciones con el fin de conseguir una mayor coherencia entre su misión empresarial y su repercusión digital sin que eso afecte fundamentalmente al tipo de estrategia y enfoque establecidos hasta el momento.

A través de NVIVO11 se ha realizado un proceso de categorización de los datos obtenidos a través de los análisis de los atributos de la marca, estrategias y palabras clave. Con los resultados alcanzados se han marcado las pautas que conforman el lenguaje, mensaje e imágenes dirigidos a consumidores digitales y prosumidores (Toffler, 1989).

\subsection{Material}

Los materiales de análisis se han obtenido teniendo en cuenta el sector de la moda, la misión de ECOALF, su labor medioambiental a través de su innovación, de las entrevistas tanto al presidente fundador de ECOALF como a su directora de comunicación; la Web corporativa; la observación de la actividad corporativa en las RRSS oficiales de Facebook, Instagram y Twitter desde el mes de diciembre de 2013 hasta diciembre de 2018. En total se trata de unas 3.000 publicaciones digitales en 
forma de imágenes analizadas, cómputo en las que se contemplan además breves contenidos audiovisuales, y los espacios físicos de los puntos de venta, los productos y sus etiquetas, entre otros.

\section{Resultados y discusión}

\subsection{Análisis de atributos}

A continuación, se observarán los atributos identificados en la marca para su análisis. Éstas señalarán el rumbo de las estrategias que marcan el tipo de contenido publicado por ECOALF, los elementos que convergen en él y el tipo de publicación que se emite según la combinación de estos componentes.

En la Tabla 1 se muestran los atributos y características que se identifican en la marca a través de las publicaciones en sus Redes Sociales. Principalmente han resultado tres que responden a Innovación, Sostenibilidad e Historia. Cada uno de ellos compone un porcentaje de aparición dentro del 100\% de las publicaciones analizadas.

Tabla 1. Atributos analizados en el Software Nvivol1.

\begin{tabular}{|c|c|c|}
\hline Atributos & Descripción del atributo & \% Aparición \\
\hline Innovación & $\begin{array}{l}\text { La innovación, según Girón (2014), Fionda y Moore } \\
\text { (2008) y Okonkwo (2007), es una de las características } \\
\text { que definen una marca de lujo debido a que éste es un } \\
\text { concepto vivo, cambiante y toda empresa que quiera } \\
\text { comercializarlo debe estar en constante evolución } \\
\text { innovando (Lipovetsky, 2012). } \\
\text { En esta línea, ECOALF innova en el proceso de } \\
\text { consecución de la materia prima. Un método pionero en el } \\
\text { mundo que aspira a cambiar un patrón de comportamiento } \\
\text { en el tejido empresarial de la moda. }\end{array}$ & $48,5 \%$ \\
\hline Sostenibilidad & $\begin{array}{l}\text { En } 1988 \text { la Comisión Mundial sobre el Medio Ambiente y } \\
\text { el Desarrollo (CMMAD) especifica que "el desarrollo } \\
\text { sostenible es el que satisface las necesidades de una } \\
\text { generación presente sin comprometer las necesidades de } \\
\text { las generaciones futuras". Esta tesis está apoyada también } \\
\text { en las ideas de Bendell y Kleanthous (2012), y Gardetti y } \\
\text { Muthu (2016). } \\
\text { "Haría referencia al hecho de defender favorablemente un } \\
\text { proceso económico que sostiene el entorno en el que se } \\
\text { desarrolla y no tanto que se mantiene por sí mismo" } \\
\text { (Benavides, 2012, p. 96). } \\
\text { Uno de los objetivos de ECOALF es precisamente que su } \\
\text { público disfrute de una prenda sin perjudicar el entorno en } \\
\text { el que se produce y utiliza. }\end{array}$ & $28,8 \%$ \\
\hline Historia & $\begin{array}{l}\text { Diversos autores, entre los que destacan Aiello y Donvito } \\
\text { (2006), Czellar (2001), } \\
\text { Fionda y Moore (2008), Kapferer (1997) y Sicard (2007), } \\
\text { consideran que la historia es un atributo propio de una } \\
\text { marca. } \\
\text { En el caso específico de ECOALF, la historia no la de la } \\
\text { marca sino la relativa al patrimonio y al legado que la } \\
\text { empresa y su actividad económica van a conservar a lo } \\
\text { largo del tiempo. }\end{array}$ & $22,7 \%$ \\
\hline
\end{tabular}

Fuente: elaboración propia. 
Según el criterio de los autores mencionados en la tabla 1, estos son algunos de los atributos que, con su presencia, demuestran su sintonía con la inspiración creativa de la marca y el reflejo de los ODS. A continuación se establece la cadena de pensamiento que arrojan estos datos sobre el rumbo marcado por ECOALF, marca que se distingue por su objetivo de favorecer la conservación del legado natural, es decir, su historia (atributo con el menor porcentaje de aparición dentro del total de publicaciones analizadas); para hacerlo se sirve de la innovación (mayor porcentaje de publicaciones) de un material que sea sostenible y en consecuencia exclusivo dado su origen y materia prima única ya que los plásticos utilizados para su producción proceden de diferentes productos y han sido rescatados de distintas aguas alrededor del mundo como el Mar Mediterráneo, Océano Atlántico u Océano Índico, entre otros.

\subsection{Estrategias}

La marca conjuga en sus publicaciones innovación, sostenibilidad e historia, no solo corporativa sino en relación con el entorno natural. Estos atributos se trasladan al consumidor de manera ordenada y equilibrada, para ello surgen las estrategias. A través del análisis de las imágenes y los textos (dentro de los cuales se contemplan los hashtags o etiquetas propias de las Redes Sociales) se ha percibido que cada una de ellas habla de una parte de la marca, de uno de sus atributos en especial y del resto en general persiguiendo, con la dominancia de uno sobre los otros, un fin concreto que la diferencia del resto de publicaciones. La estrategia consiste en dar sentido a ese contenido emitido.

Se han identificado tres estrategias de comunicación de ECOALF que son: la comercial, la de sensibilización y la informativa.

Estas estrategias tienen en cuenta los atributos, los objetivos económicos, medioambientales y la información que la marca genera dentro del tejido empresarial y social.

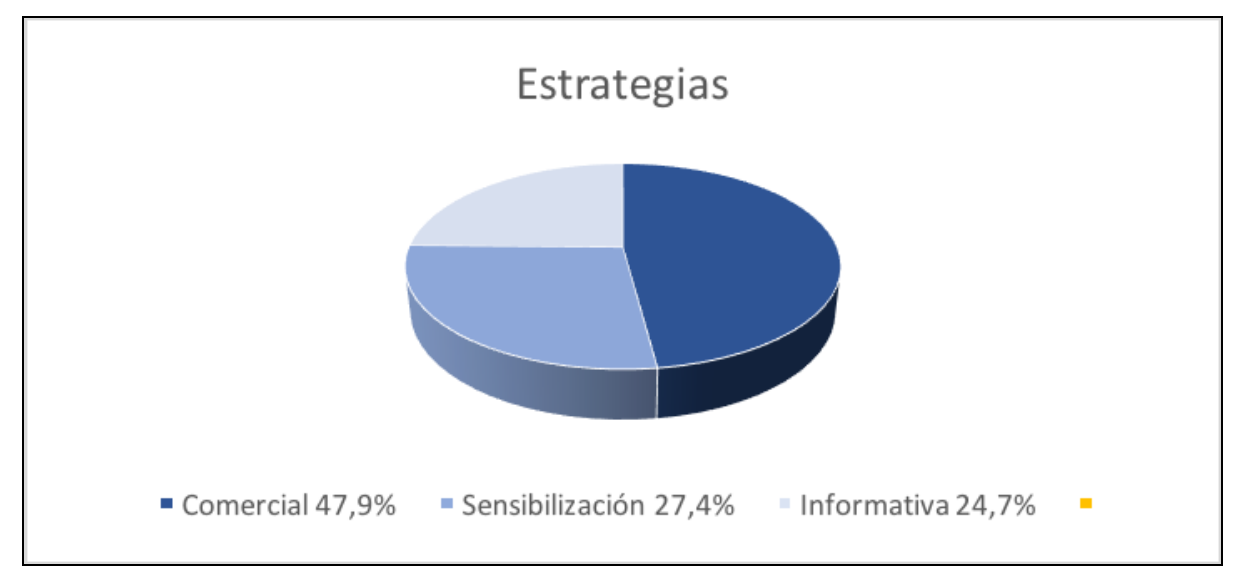

Figura 1: estrategias analizadas en el Software Nvivo11.

Fuente: elaboración propia.

Las estrategias que se reflejan en la figura 1 están acompañadas de un porcentaje que expresa la presencia que tiene cada una de las tres en la globalidad de la comunicación de ECOALF. Cada una de ellas se desarrollarán en los siguientes apartados con la exposición de ejemplos de imágenes, texto y etiquetas o hashtag que también se modifican según el tipo de estrategia, aunque hay dos que son transversales a las tres: la marca, \#ECOALF, y su leitmotiv \#becausethereisnoplanetB.

Cabe mencionar que sus estrategias en Instagram, Twitter y Facebook son las mismas. Lo que puede diferir es que Facebook y Twitter suelen tener contenidos con un porcentaje mayor en torno a la 
información a diferencia de Instagram que acoge las tres estrategias siendo mayoritarias la de sensibilización y la comercial aunque sin una diferencia sustancial.

\subsubsection{Estrategia comercial}

La marca emite sus mensajes, publicaciones y contenido a la comunidad digital con diferentes propósitos. Éstos se erigen como estrategias siendo una de ellas la comercial, donde la marca publica sus productos, sus fichas técnicas y los expone con propósito de venta. El contenido de esta estrategia da especial importancia al atributo de la innovación, por ello los textos que acompañan a las imágenes suelen incluir un ejercicio de trazabilidad de la prenda para explicar al usuario datos técnicos del tejido, detalles como el impacto medioambiental de la elaboración del objeto o el impacto de su consumo o su repercusión en el entorno natural.

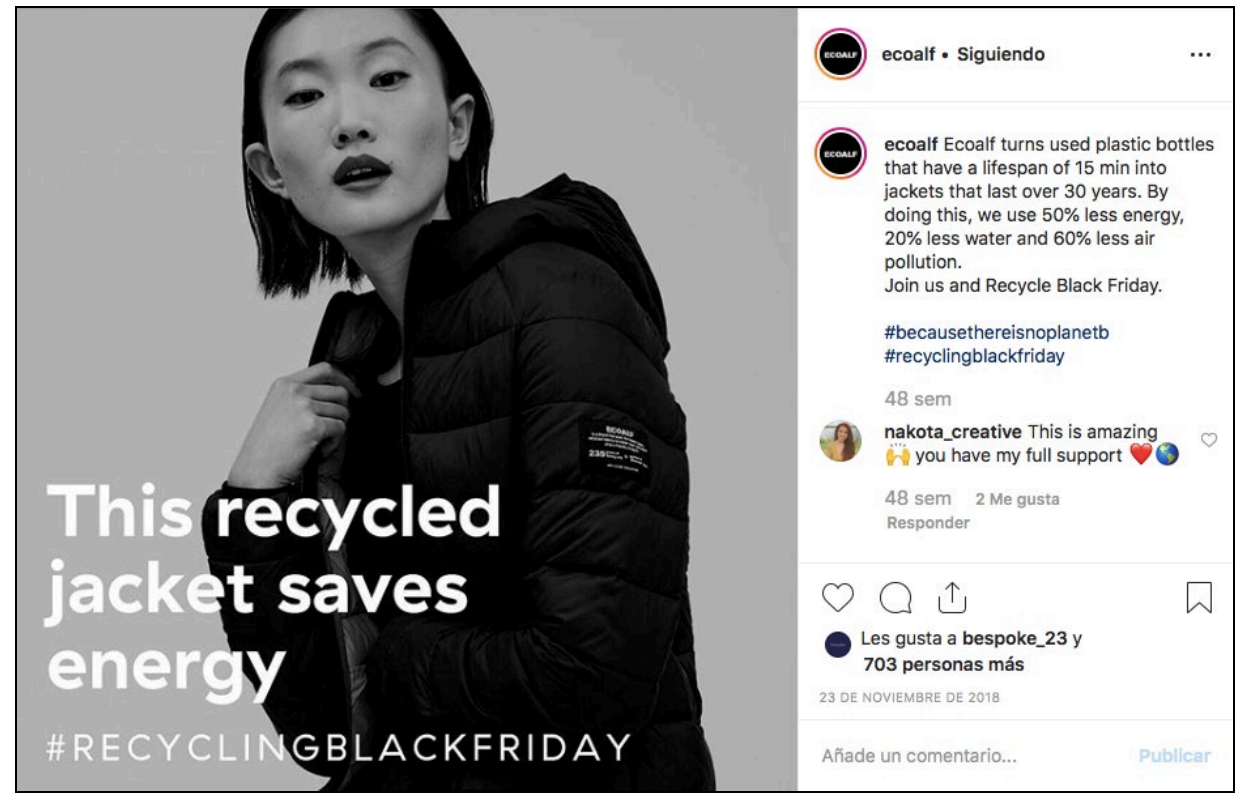

Figura 2: chaqueta hecha con botellas de plástico que en su producción ha ahorrado agua, energía y polución al medio ambiente global.

Fuente:@ecoalf en Instagram 2018.

En este proceso de comercialización siempre aparece el atributo de la innovación en los productos de la marca mostrados en las imágenes en tres contextos: expuestos, llevados por modelos o siendo utilizados por celebrities. Estos personajes conocidos en la sociedad como es el caso del actor Richard Gere o la Reina Emérita de España, Doña Sofía, es una herramienta de promoción clásica y que suele generar mayor credibilidad que la publicidad. (Kotler \& Keller, 2007).

\subsubsection{Estrategia de sensibilización}

Bajo una visión próxima al movimiento acuñado como Slow Fashion por Fletcher en 2007 (Fletcher, 2014) ECOALF publica contenido en torno a una estrategia de sensibilización medioambiental donde el atributo de la sostenibilidad sobresale a través de los siguientes mensajes:

- Eliminar la temporalidad de las prendas para fomentar la atemporalidad de la ropa en el armario y por tanto hacer sostenible el consumo junto con la producción y el vertido de deshechos al medioambiente. 


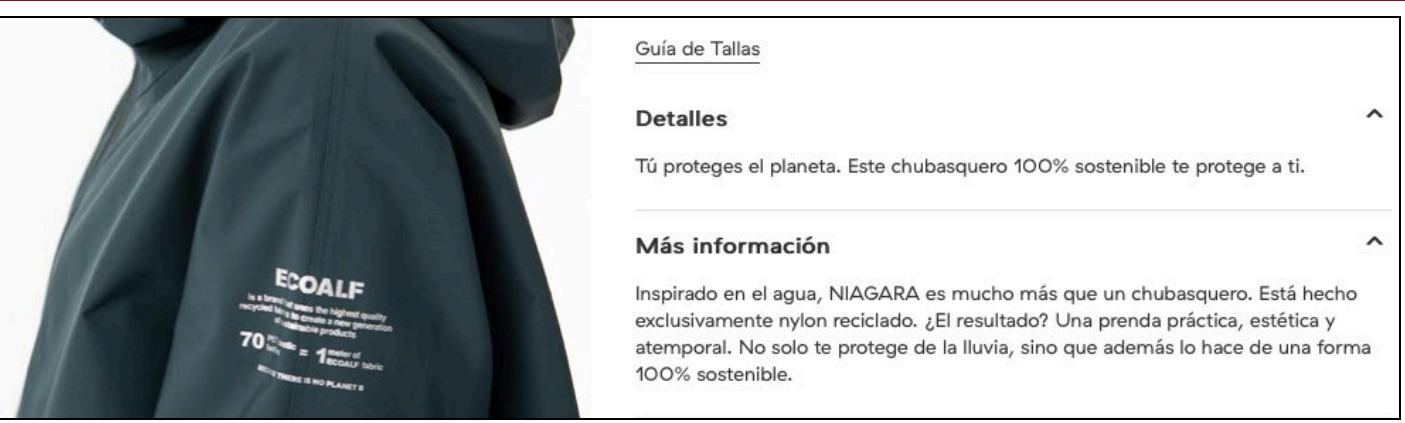

Figura 3: la atemporalidad de la prenda en el discurso comercial de la marca. Fuente:@ecoalf en Instagram 2017.

- No fomentar el consumo. Centra el mensaje en la calidad de la prenda y no en la cantidad con lo que favorece la sostenibilidad en los recursos naturales.

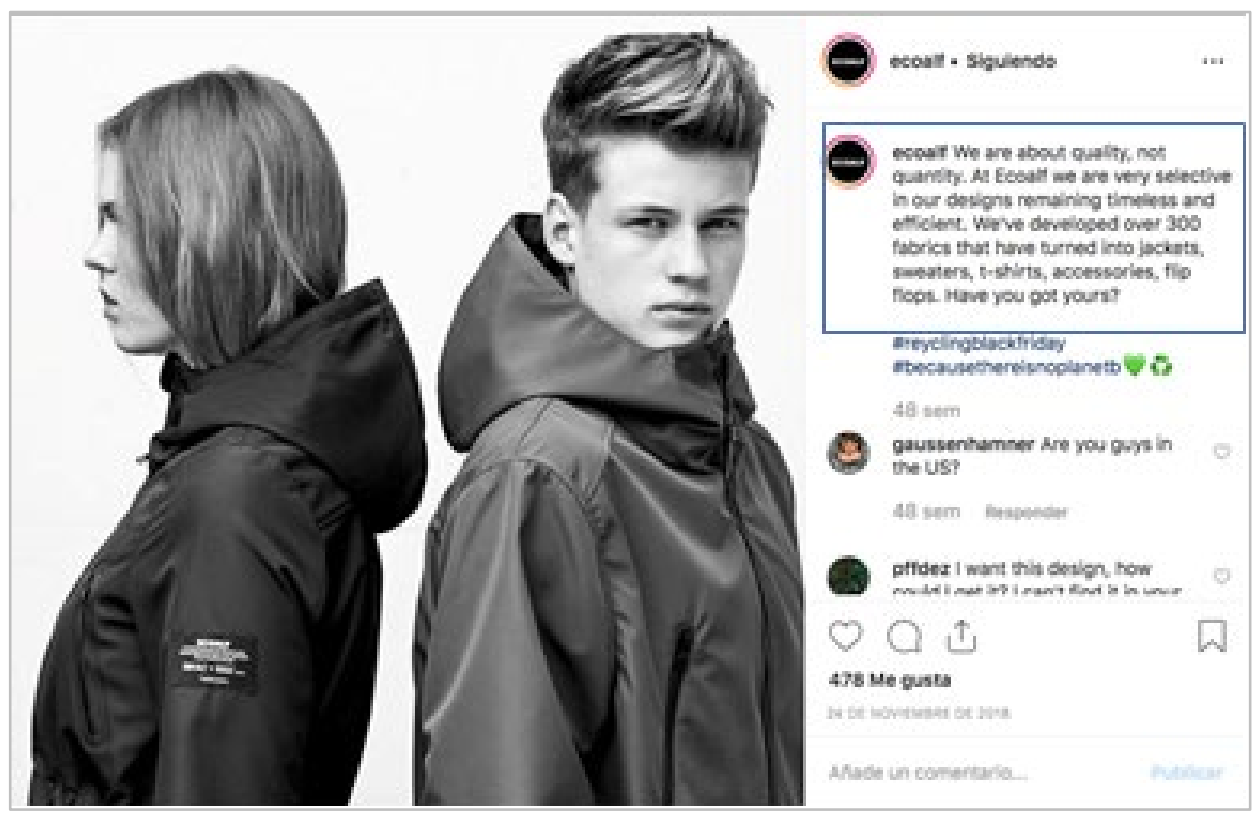

Figura 4: sensibilización de la calidad frente a cantidad.

Fuente:@ecoalf en Instagram 2018.

- La marca anima a los usuarios a inculcar valores a las futuras generaciones a través de mensajes como: "enseña a tus hijos a ser sostenibles" con imágenes donde la infancia aparece vestida con las prendas sostenibles de ECOALF en contextos naturales o con colores cercanos a la naturaleza como los verdes y azules.

Para el refuerzo de esta línea estratégica también emite mensajes que refuerzan la concienciación como el siguiente: "Hacer lo correcto, no lo fácil", un mensaje reforzado siempre por una etiqueta fija \#upcyclingtheoceans, en referencia a su sistema de limpieza de océanos y \#sustainablefashion, en referencia a la moda sostenible que producen. Ambas etiquetas en equilibrio con el atributo principal de esta estrategia, la sostenibilidad. 


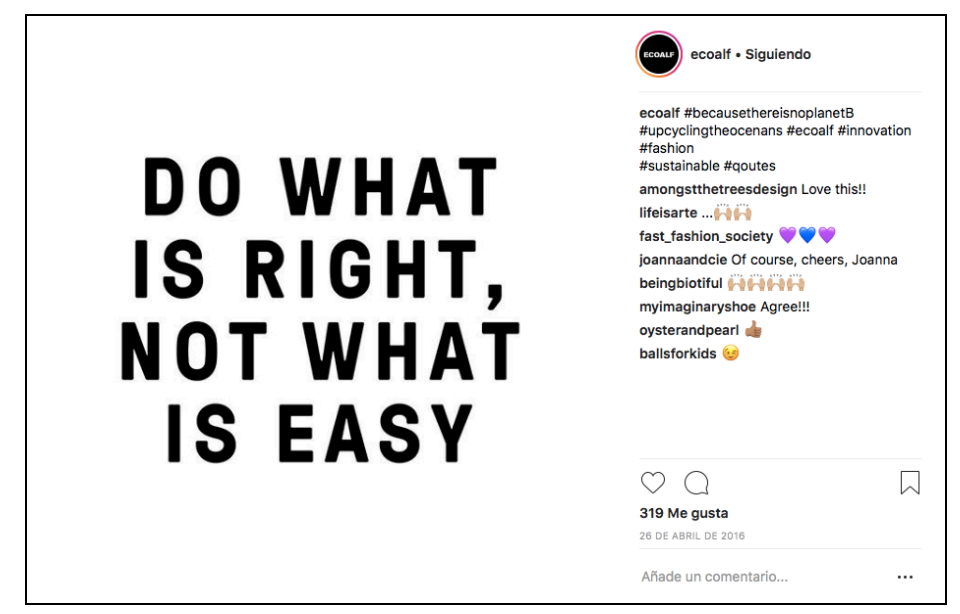

Figura 5: hacer lo correcto y no hacer lo fácil.

Fuente: @ecoalf en Instagram 2016.

El atributo más utilizado en esta estrategia de sensibilización, como ha sido anunciado, es el de sostenibilidad. Se trata de imágenes donde el arte, frases inspiracionales, escenarios sostenibles se muestran acompañados de textos que muestran un deseo de incitar un cambio hacia el estilo de vida sostenible en el consumo.

La aceptación, medida en base a la media de likes y me encanta, supera ligeramente el promedio establecido de este tipo de publicaciones.

\subsubsection{Estrategia informativa}

El contenido que se emite en relación a esta estrategia tiene como objetivo trasladar la realidad contextual que da sentido a la existencia de la marca al ámbito digital y a sus usuarios. Lejos de vender de forma directa un producto, lo que resalta es su vocación de ofrecer información para entender la marca, su implicación en la sociedad y datos sobre temas medioambientales.

En las imágenes y textos que se publican, ECOALF informa de su rechazo a las ofertas del Viernes Negro, en su lengua original Black Friday; informa del significado de las etiquetas de sus prendas, del tiempo de descomposición de una botella cualquiera utilizada para la producción de sus productos -figura 7- o de los desperdicios que hay en el mar con imágenes como la plasmada en la figura número 6.

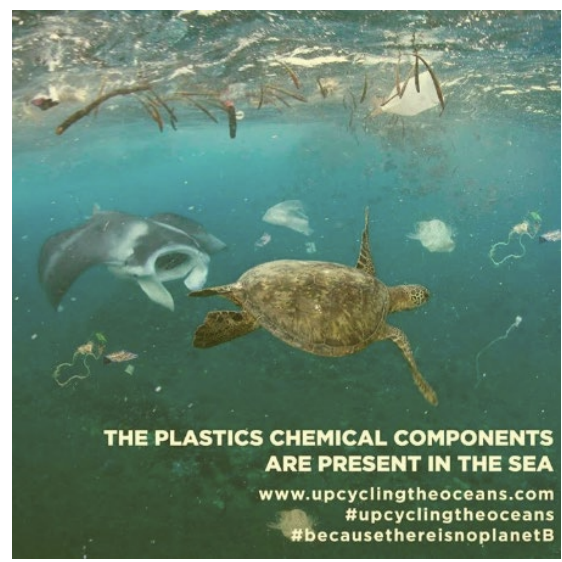

Figura 6: ECOALF informa sobre la presencia de componentes químicos en los océanos y su iniciativa para limpiarlos.

Fuente: @ecoalf en Facebook2018. 


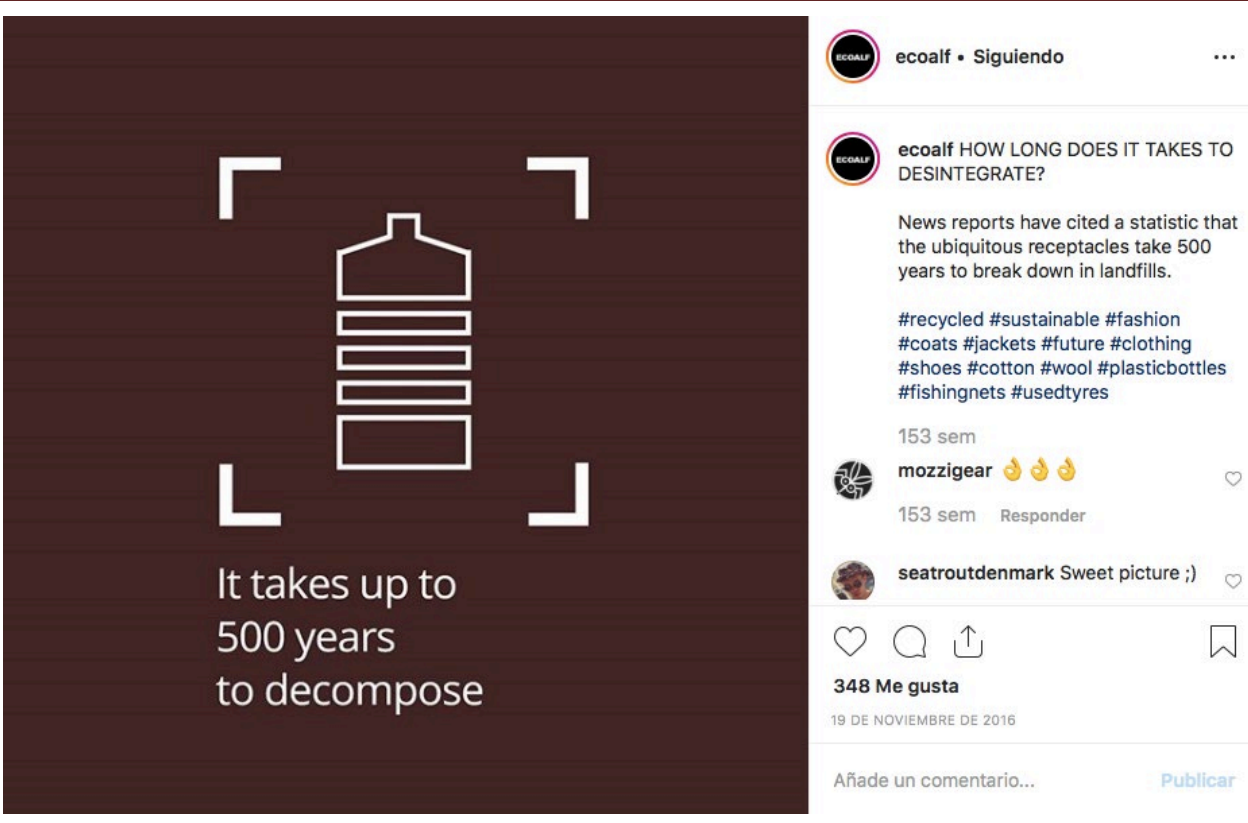

Figura 7: explicación del tiempo requerido para la descomposición de una botella de plástico.

Fuente:@ecoalf en Instagram 2016.

En esta estrategia se puede intuir cómo la marca alude al atributo de historia en la dirección de conservación de un legado natural o de los quinientos años que tarda en descomponerse una botella cuando ECOALF hace moda con ella y la recicla. La estrategia informativa, como el resto, aporta imágenes reales al usuario y datos con credibilidad y sencillez sin dejar de lado la publicity, información que los medios utilizan por su valor informativo (Cutlip \& Center, 2001 en Liberal, 2012), y que ECOALF proporciona a los medios de comunicación como ha sido el caso de la expedición de Greenpeace en 2018 a la Antártida para denunciar el calentamiento global con actores reconocidos a nivel internacional vestidos con productos de la marca para el viaje.

\subsection{Alfabetización a través de la experiencia de usuario}

Justificadas sus estrategias de contenidos se avanzará hacia el entorno digital en el que actúa a través de cuatro líneas: si facilita la conexión entre la marca y el/la usuario llamado Arquitectura de la información; la existencia de una estética común en la parte más visual como color e iconos entre otros a través del Diseño de Interacción; la Usabilidad en la organización de contenidos para estar en equilibrio con el interés comercial de la compañía; Y si la estética visual transmite los valores de marca en el Diseño Visual.

En cuanto a la Arquitectura de la Información -AI- donde contactar con la empresa se entiende como relevante al dar la posibilidad de enviar un mensaje, e incluso su dirección física de las tiendas insignia ubicadas en Madrid y Berlín además de todos los puntos de venta repartidos en Europa y Asia. Esta información es accesible de forma directa en Facebook y la Web, mientras que Instagram y Twitter son canales que indica el enlace a la web para descubrir esta información.

En el caso del Diseño de Interacción: en Facebook se invita de forma intuitiva a la interacción interracial, de géneros y diferentes segmentos poblacionales únicamente con la fotografía de portada. En cuanto a botones específicos para comprar o acceder a información variada en el menú de la izquierda fácilmente accesible, es algo donde la usabilidad es fundamental para responder tanto a la satisfacción de las personas para encontrar fácilmente lo que buscan, ya sea el contacto, el producto o 
promoción del momento. La Web e Instagram facilitan igualmente el proceso de compra mientras que Twitter representa para la marca un entorno de debate para el usuario e interacción con él con un propósito más cercano a la sensibilización que al comercial por el tipo de contenido que se publica.

La usabilidad es en general patente para la navegación, interacción y compra en la Web, Instagram y Facebook. Está en equilibro con la variedad en la emisión mensajes dirigidos a individuos que conforman los diferentes grupos de interés de la marca que están, como su actividad, en tres continentes América, Ásia y Europa. Esta población recibe bajo una misma apariencia mensajes sobre estilo de vida en torno al cuidado del medioambiente y de un consumo sostenible entre otros bajo una estética universal por su sencillez de líneas, minimalismo en sus puntos de venta que reflejan la ausencia de líneas entalladas en sus productos. El contenido que conforma el mundo de la marca online puede ser un fiel reflejo de la presión que puede llegar a ejercer el consumidor "sobre la industria, la economía y la política tiene la suficiente influencia para promover un cambio generalizado y permitir buscar soluciones más adecuadas para la preservación del medio ambiente y de la vida en el planeta" (Manuel, 2011, p. 9).

Por último, se señalará el diseño visual, donde las propias creatividades reflejan la misión corporativa junto con la misión empresarial como se muestra en la siguiente creatividad para promocionar y dar visibilidad al hashtag \#upcyclingtheoceans que lleva el nombre de su proyecto principal dedicado a la limpieza de plástico de los océanos.

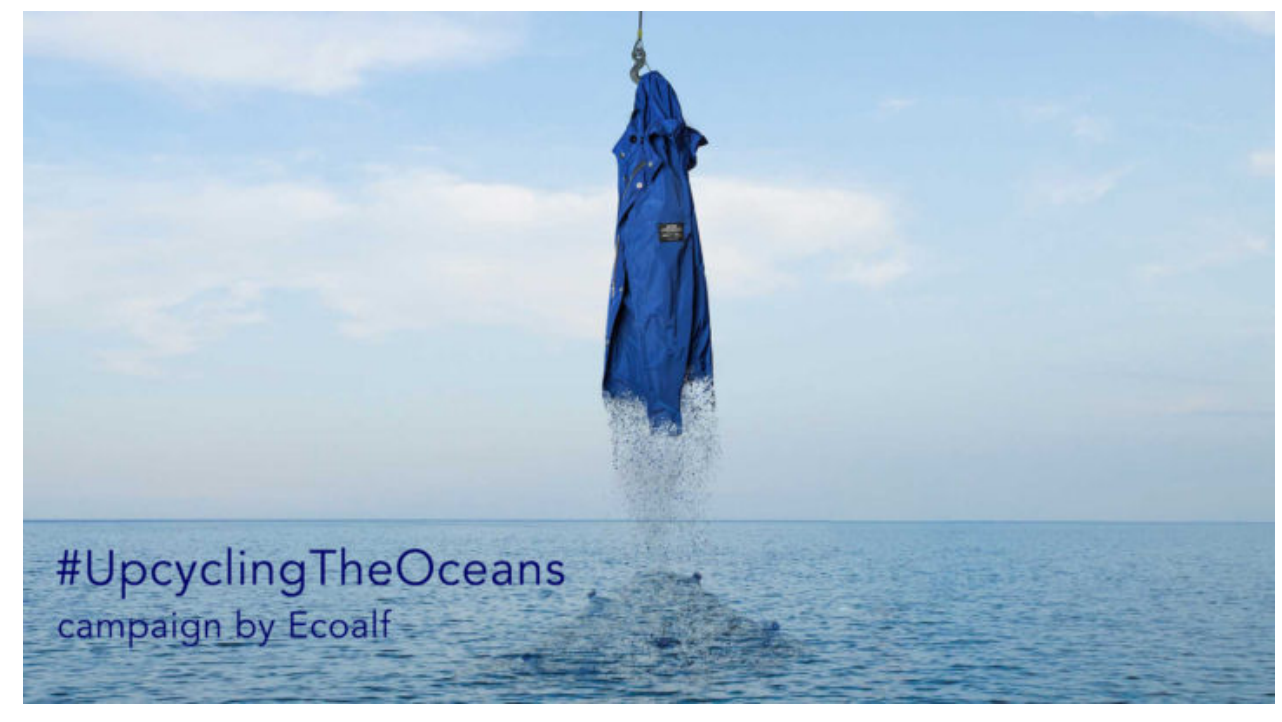

Figura 8: Fundación ECOALF.

Fuente: López, T. (2018).

https://www.ekoenergy.org/the-fashion-industrys-duty-to-lead-the-change-towards-sustainability/

\subsection{Frecuencia y representación de relaciones}

En la siguiente nube de palabras generada por NVIVO11 se pueden apreciar los cien conceptos que aparecen con mayor frecuencia. La nube de palabras representa de forma visual las palabras del discurso analizado atendiendo a su presencia, su relación con las palabras próximas y su frecuencia. Esto representa la importancia de los términos en relación con otros por su proximidad y frecuencia de presencia a través del tamaño, cercanía y/o lejanía entre ellas, centralidad, y la intensidad. 


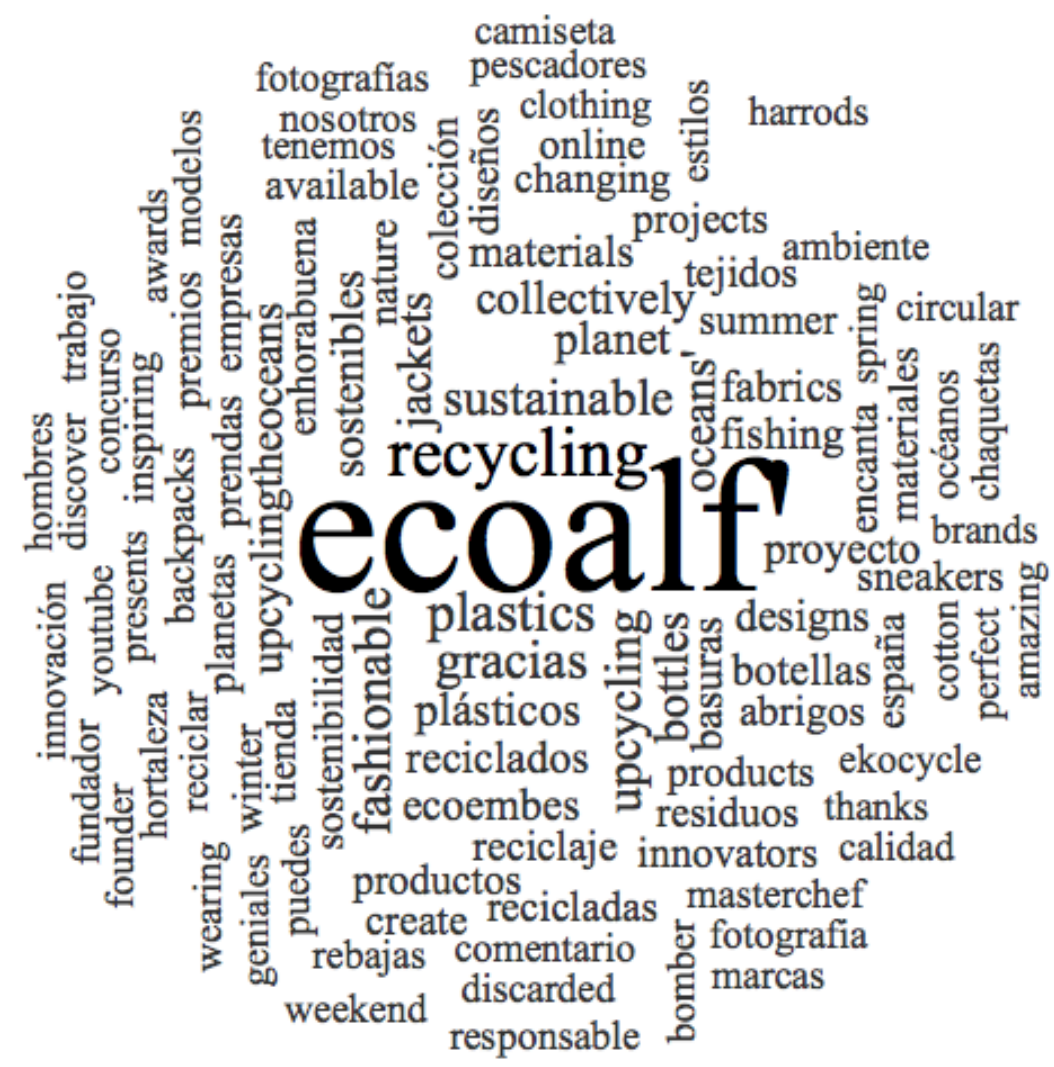

Figura 9: nube de palabras más utilizadas en el discurso digital de ECOALF.

Fuente: elaboración propia a través de NVIVO11.

Con el fin de concretar el lenguaje utilizado, se ha procedido a extraer las cinco palabras más frecuentes en el universo digital de la marca. Se pueden apreciar en la tabla 2 junto con su porcentaje de aparición

Tabla 2. Palabras más mencionadas según análisis en el Software Nvivo11.

\begin{tabular}{|l|l|c|}
\hline \multicolumn{2}{|c|}{ Las cinco palabras más usadas en las publicaciones online de ECOALF } \\
\hline Posición & \multicolumn{1}{|c|}{ Palabra } & \% de uso \\
\hline 1 & ECOALF & $3,05 \%$ \\
\hline 2 & Recycled -reciclado- & $0,60 \%$ \\
\hline 3 & Moda-fashionable- & $0,36 \%$ \\
\hline 4 & Plastic-plástico- & $0,32 \%$ \\
\hline 5 & Gracias & $0,31 \%$ \\
\hline
\end{tabular}

Fuente: elaboración propia.

Estos datos en torno a los conceptos más frecuentes en el discurso de la marca enlazan con las etiquetas utilizadas y atributos principales en la narrativa global ya que apuntan a las estrategias a través de las cuales se dividen las publicaciones.

ECOALF sobresale en la nube de palabras y su porcentaje de frecuencia la confirma como la palabra más utilizada y por tanto ratifica la marca como elemento principal para comercializar el producto, y erigirse como impulsora de información relativa a su estilo de vida sensibilizada con el medioambiente. 
Para finalizar, se propone un gráfico que representa la correspondencia entre atributos, estrategias y palabras según porcentajes obtenidos en el análisis del Software Nvivo11. Se establece una conexión entre todos los elementos con el fin de dilucidar la existencia de una pertenencia a un universo común.

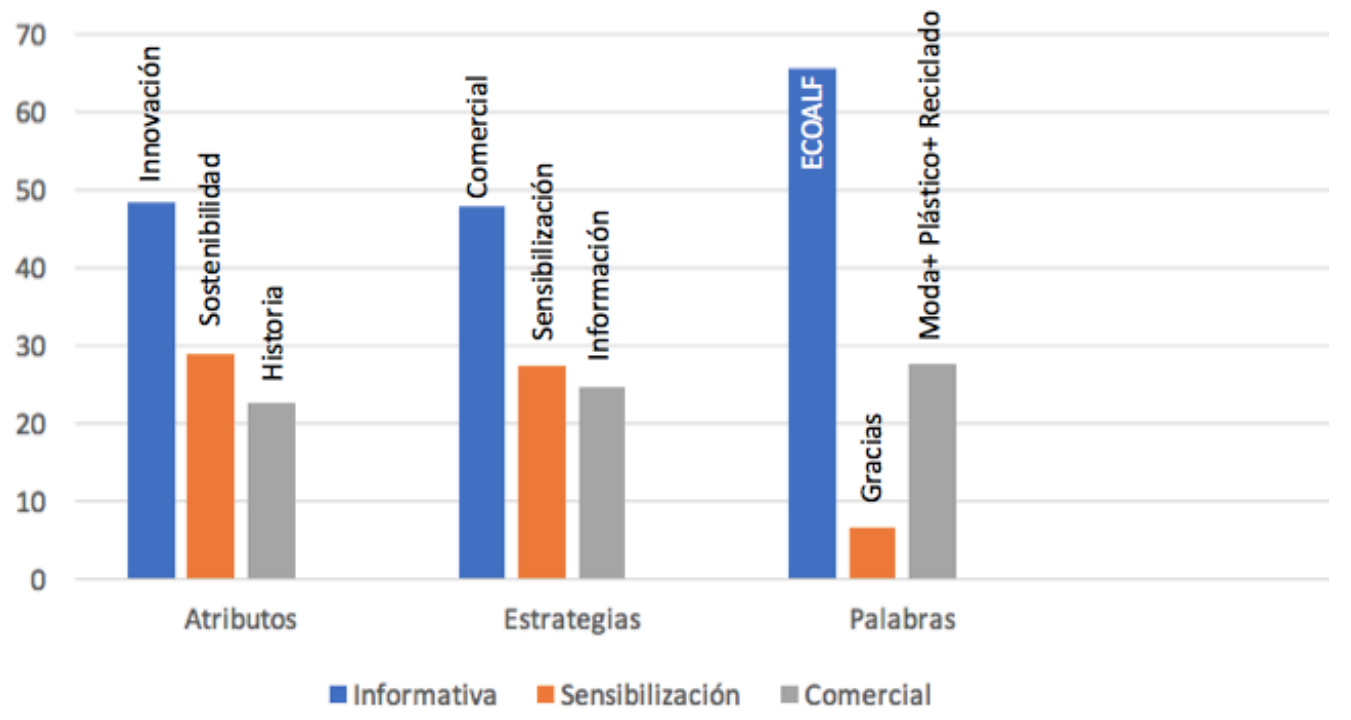

Figura 10: correspondencia entre términos analizados.

Fuente: elaboración propia.

Tiene tres agrupaciones que son atributos, estrategias y palabras. Cada grupo tiene tres elementos que quedan definidos por un color: el azul, el naranja y el gris. El azul tiene el mayor grado de presencia en cada uno de los grupos. Siendo el naranja un segundo nivel y el gris en el tercero. El azul corresponde a la innovación, a la estrategia comercial y a la palabra ECOALF, la más utilizada. De ahí que el atributo de innovación y la estrategia comercial sean dos líneas profundamente ligadas a la marca. El naranja también se relaciona con ECOALF pero aparece más estrechamente relacionada entre el atributo de sostenibilidad, la estrategia de sensibilización y la palabra Gracias. Y por último se relaciona entre sí la historia, la información y los términos moda, plástico y reciclajes todos ellos de color gris. Esto nos da la idea de la organización que ECOALF tiene con sus atributos, estrategias y sus palabras clave. ECOALF está siempre presente y recoge las interrelaciones que se establecen entre los grupos y entre sí en relación con ECOALF.

Una vez más se reitera la coexistencia de diferentes tipos de publicaciones que surgen de las diferentes combinaciones de porcentajes de los mismos elementos establecidos por la marca, sus atributos y sus fines fundacionales.

\section{Conclusiones}

A partir de los objetivos planteados se identifica cómo a través de herramientas de comunicación digitales, una empresa de moda convierte su propio proceso de producción en material audiovisual de sensibilización, comercialización y alfabetización mediática y digital, de ahí que su fundador, confirme que ellos son una empresa storydoing porque cuentan lo que hacen y cómo lo hacen.

Lo hacen a través de tres estrategias cuyos elementos se entrelazan para dar como resultado un universo de la marca susceptible de ser aceptado por cualquier persona por su carácter universal de conceptos y las ideas a los que se acoplan. 
El análisis de las estrategias comunicativas que emplea la marca para informar a los receptores a través de sus mensajes, muestra que las publicaciones son sensibles a la sociedad ya que tratan un hecho común, como lo es la contaminación oceánica. Además, están al alcance de cualquier usuario de medios digitales, sin barreras de acceso al contenido por la composición de imagen, vocabulario empleado y valores universales.

ECOALF, alude a los Objetivos de Desarrollo Sostenible (ODS) en sus mensajes online de forma directa. En sus publicaciones aparecen el 47\% epígrafes de la agenda 2030 de Naciones Unidas. Este porcentaje resulta de trabajar ocho de los diecisiete objetivos. Estos son: punto 6 de "Agua Limpia y Saneamiento"; el número 9 en relación a la "Industria, Innovación e Infraestructura"; el 11 llamado "Ciudades y Comunidades Sostenibles"; el objetivo 12 que se define como "Producción y Consumo Responsables"; el número 13 referente a "Acción por el clima" sin olvidar el número 14 "Vida Submarina" además del 17 "Alianzas para lograr los objetivos".

Los porcentajes del reflejo de ODS en su estrategia de comunicación digital confirman su transmisión de valores y atributos, como la innovación por medio de la conversión de basura oceánica en prendas de diseño, con la publicación de sus materiales online, ya sea a nivel fotográfico, audiovisual o textual.

Los productos de la marca y sus promociones audiovisuales impulsan la concienciación medioambiental a nivel mundial por la aparición de diferentes puntos geográficos y la multiculturalidad de sus modelos y variedad de los protagonistas en las publicaciones concebidas para diferentes consumidores de moda, de RRSS, ecologistas, líderes culturales y cazadores de tendencias entre otros. Se trata del descubrimiento de la fuerza del User Experience de ECOALF sobre todo en las creatividades y contenidos audiovisuales que tienen siempre como protagonistas su producto de forma explícita o implícita en cuyo caso se hace presente a través del lenguaje escrito.

Su lenguaje es directo "actúa ahora" o "no hay un planeta B". La palabra Gracias, a pesar de ser una de las cinco más frecuentes en el discurso general tiene la presencia más débil en relación al resto lo que puede conducir a la conclusión de que aún queda pendiente una posible maduración de la estrategia de sensibilización por parte de la marca en lo referido a su lenguaje. Esto no es un impedimento para que el discurso oficial invite al usuario a que lo haga propio y pueda seguir extendiéndolo y convirtiéndolo en prosumidor de su propia comunidad. De esta forma la marca consigue la creación de microcomunidades que alcanzan a otros usuarios no localizados por la propia marca. Por tanto, lleva a cabo una labor de alfabetización digital ya que impulsa al público a participar del medio por el que informa digitalmente no solo contenido con propósito comercial creado por la marca sino noticias e información que señalan como referente al propio ECOALF: noticias de televisión en canales de Europa, Asia y América sobre su alcance a los cinco continentes, premios concedidos, explicaciones de la repercusión en la historia de objetos de uso común como una botella, entre otros datos.

En definitiva, ECOALF transmite su misión empresarial con coherencia en las redes y esa coherencia de refleja en los impactos que no alcanza a su control a través de las apariciones en canales que trascienden a la comunidad digital donde otros son autores ajenos al control de la marca. 


\section{Referencias}

Asociación para la investigación de medios de comunicación (2018). Audiencia de Internet. http://internet.aimc.es/index.html\#/main/evousers

Benavides, J., Fernández, J. L., y Urtiaga, A. (2012). Glosario sobre Responsabilidad Social para la Investigación y el Debate Terminológico. https://www.comillas.edu/images/eticaeconomica/Glosariosobreresponsabilidad.pdf

Camps, V. (2003). Sociedad de la información y ciudadanía, en I. Aguaded (coord.), Luces en el laberinto audiovisual. Conferencia llevada a cabo en Congreso Iberoamericano de Comunicación y Educación, Huelva, España.

CMMAD (1988). Informe Brundtland. http://www.ecominga.uqam.ca/PDF/BIBLIOGRAPHIE/GUIDE LECTURE 1/CMMADInforme-Comision-Brundtland-sobre-Medio-Ambiente-Desarrollo.pdf

Fletcher K.; Tham (Eds.) (2014). Routledge Handbook of Sustainability and Fashion. Routledge.

Fondevila, J. F. (2013). Periodismo ciudadano y cloud journalism: un flujo necesario en la Sociedad de la Banda Ancha. Comunicación y hombre, (9), 25-41.

Francés, P. (2005). Responsabilidad Social de las Empresas: Fundamentos y enfoque de la gestión responsable. Forética.

Gardetti, M. \& Muthu, S. (Eds.). (2016). Handbook of Sustainable Luxury Textiles and Fashion. Springer.

Girón, M. (2009). Secretos de Lujo. LID Editorial.

Gilster, P. (1997). Digital literacy. Wiley Computer Pub.

González, E. (2007). La teoría de los stakeholer: Un puente para el desarrollo práctico de la ética empresarial y de la responsabilidad social corporativa. Veritas: revista de filosofía y teología, (17), 205-224. https://n9.cl/slam

Gutiérrez, A. (2003). Alfabetización Digital: algo más que botones y teclas. Editorial Gedisa. https://n9.cl/jxql

Gutiérrez, A., y Tyner, K. (2012). Educación para los medios, alfabetización mediática y competencia digital. Revista Comunicar, 19(38), 31-39. https://n9.cl/8vqg

Hassan, Y., y Martín, F.J. (2005). La Experiencia del Usuario. No Solo Usabilidad: revista sobre personas, diseño y tecnología, (4). http://www.nosolousabilidad.com

Honoré, C. (2004). Elogio de la lentitud. Un movimiento mundial desafía el culto a la velocidad. RBA libros. https://n9.cl/q1aji 
International Standard ISO (2015). Ergonomics of human system interaction-Part 210: Humancentred design for interactive systems (formerly known as 13407). International Standardization Organization (ISO). Switzerland. https://www.sis.se/api/document/preview/912053/

Jenkins H., Shresthova S., Gamber, L., Kligler N., \& Zimmerman A. (2006). By Any Media Necessary: The New Youth Activism. NYU Press.

Jenkins, H., Ford, S., y Green, J. (2015). Cultura Transmedia: la creación de contenido y valor en una cultura en red. Editorial Gedisa.

Kapferer, J-N. (2006). FAQ. La marque. La marque en questions: résponses d'un spécialiste. Dunod.

Knapp Bjerén, A. (Coord.) (2003). La Experiencia del Usuario. Anaya Multimedia.

Lacasa, P., De La Fuente, J., y Méndez, L. Ed. (2015). Redes sociales en la adolescencia. Crear y participar. Palabras e Ideas.

Lacasa, P. (2018). Expresiones del futuro. Cómo se comunicarán las próximas generaciones. Morata.

Lastra, A. (2016). El poder del prosumidor. Identificación de sus necesidades y repercusión en la producción audiovisual transmedia. Revista Icono14, 14(1), 71-94. https://www.icono14.net/ojs/index.php/icono14/article/view/902

Lazcano, E. (2017). Comunicación Emocional. LID Editorial.

Lipovetsky. G. (2002). La era del vacío. Anagrama.

López, T. (2018). El deber de la industria de la moda de liderar el cambio hacia la sostenibilidad. Ekoenergy. https://www.ekoenergy.org/the-fashion-industrys-duty-to-lead-the-change-towardssustainability/

Magnier, L., Mugge, R., \& Schoormans, J. (2019). Turning ocean garbage into products-Consumers' evaluations of products made of recycled ocean plastic. Journal of cleaner production, (215), 8498.

Manuel, V. (2011). Los caminos del reciclaje. NEED Ediciones.

Mc Luhan, H. M., McLuhan, M., y Nevitt, B. (1972). Take today: The executive as dropout. [Don Mills, Ont.] Longman Canada

Mir, P. (2016). Brand.com: reputación de marcas y social media. EUNSA.

Moreno, A., y Capriotti, P. (2006). La comunicación de las empresas españolas en sus webs corporativas. Análisis de la información de responsabilidad social, ciudadanía corporativa y desarrollo sostenible. ZER: Revista de Estudios de Comunicación, 11(21).

Moreno, M. (2015). Cómo triunfar en las Redes Sociales. Ediciones Gestión. 
Nielsen Norman Group (2003). The Definition of User Experience (UX). World Leaders in Research-Based User Experience. http://www.nngroup. com/about/userexperience.html

Okonkwo, U. (2005). Luxury Fashion Branding: trends, tactics, techniques. Palgrave Macmillan.

ONU (2020). Objetivos de Desarrollo Sostenible.

https://www.un.org/sustainabledevelopment/es/objetivos-de-desarrollo-sostenible/

Otaduy, J. (2012). Genoma de Marca. LID Editorial.

Ros, V. J., y Castelló, A. (2012). La comunicación de la responsabilidad en los medios sociales. Revista Latina de Comunicación Social, (67), 1. https://dialnet.unirioja.es/servlet/articulo?codigo $=3802438$

Senthilkannan S. (Ed.). (2016). Textiles and Clothing Sustainability: Recycled and Upcycled Textiles and Fashion. Springer.

Saviolo, S., y Testa, S. (2007). La Gestión de las Empresas de Moda. GG Moda.

Toffler, A. (1990). The Third Wave Plaza \& Janés.

Wanders, A. T. (2009). Slow Fashion. Niggli.

Winner, L. (2004). Technology as forms of life, en: Kaplan, D. M. (Ed.). Readings in the philosophy of technology, (p. 104). Rowman \& Littlefield.

\section{AUTORES:}

\section{Bienvenida Araceli Parres Serrano}

Doctoranda y Profesora Asociada en la Facultad de Filosofía y Letras de la Universidad de Alcalá. Es Licenciada en Periodismo por la Universidad Cardenal Herrera-CEU, Master en Comunicación Política y Corporativa por las Universidades de Navarra y The George Washington. Durante más de diez años su carrera profesional se ha desarrollado en el ámbito más amplio de las Relaciones Institucionales y Eventos en los mercados de Asia, Europa y América Latina. Ahora mismo compagina su responsabilidad en el departamento de Desarrollo de una Fundación con su investigación sobre el mensaje social de las marcas de lujo en sus comunicaciones online.

araceli.parres@edu.uah.es

Orcid ID: https://orcid.org/0000-0002-6334-5730

Google Scholar: https://scholar.google.com/citations?hl=en\&user=dbTfVigAAAAJ

Researchgate: https://www.researchgate.net/profile/Araceli_Parres

\section{Francisco García García}

Catedrático de Comunicación Audiovisual y Publicidad por la Universidad Complutense de Madrid desde el año 1995 y profesor emérito de la UCM. Ha publicado numerosos artículos y libros relacionados con la comunicación, la creatividad, la narrativa, la educación y la retórica y sus interacciones con las nuevas tecnologías de la información y la comunicación. Es editor de las revistas científicas Icono 14 y Prisma Social, ambas indexadas en Scopus, así como de otras publicaciones como Creatividad y Sociedad. En su trayectoria destaca la dirección de más de 165 
tesis doctorales y de diversos proyectos de investigación $\mathrm{I}+\mathrm{D}+\mathrm{i}$ de obtención competitiva a nivel nacional.

fgarciag@ucm.es

Índice H: 56

Orcid ID: https://orcid.org/0000-0001-5394-4804

Google Scholar: https://scholar.google.com/citations?user=as2gqFUAAAAJ\&hl=es

Researchgate: https://www.researchgate.net/profile/Francisco_Garcia43

Academia.edu: https://ucm.academia.edu/FranciscoGarc\%C3\%ADaGarc\%C3\%ADa

Dialnet: https://dialnet.unirioja.es/servlet/autor? codigo $=524771$

Scopus: https://www.scopus.com/authid/detail.uri?authorId=55439107500

Idref: https://www.idref.fr/136393705

\section{Eva Matarín Rodríguez-Peral}

Socióloga y Doctora en Ciencias de la Información. Posee un máster en Comunicación Corporativa e Institucional. En el ámbito educativo posee el Certificado de Aptitud Pedagógica (CAP), formación en Dirección y Gestión de Proyectos e-learning, además de contar con el postgrado de Especialista en Investigación Social Aplicada y Análisis de Datos impartido por el Centro de Investigaciones Sociológicas. En su trayectoria profesional destaca la puesta en marcha de la Fundación iS+D y la coordinación inicial de la Revista de investigación Prisma Social. Profesora del área de Sociología de la Universidad Rey Juan Carlos y Coordinadora académica de apoyo del Máster Universitario en Educación Inclusiva e Intercultural en la Universidad Internacional de La Rioja.

eva.matarin@urjc.es

Índice H: 2

Orcid ID: https://orcid.org/0000-0002-1701-3911

Google Scholar: https://scholar.google.es/citations?user=Z77V01cAAAAJ\&hl=es\&oi=ao

Researchgate: https://www.researchgate.net/profile/Eva_Matarin_Rodriguez-Peral

Academia.edu: https://ucm.academia.edu/EMatar\%C3\%ADn 